\title{
A numerical study of the generation and propagation of internal solitary waves in the Luzon Strait
}

\section{Étude numérique de la génération et de la propagation d'ondes solitaires internes dans le détroit de Luzon}

\author{
Shuqun Cai *, Xiaomin Long, Zijun Gan \\ LED, South China Sea Institute of Oceanology, The Chinese Academy of Sciences, Guangzhou 510301, China
}

Received 14 August 2001; received in revised form 6 November 2001; accepted 12 November 2001

\begin{abstract}
A new composite model, which consists of a generation model of the internal tides and a regularized long wave propagation model, is presented to study the generation and evolution of internal solitary waves in the sill strait. Internal bores in the sill strait are first simulated by the generation model, and then the internal tidal field outside of the sill region is given as input for the propagation model. Numerical experiments are carried out to study the imposing tide, depth profile, channel width and shoaling effect, etc., on the generation and evolution of internal solitary waves. It is shown that only when the amplitude of internal tide at the forcing boundary of the propagation model is large enough that a train of internal solitary waves would be induced. The amplitude of the imposing tide in the generation model, shoaling effect, asymmetry of the depth profile and channel width have some effects on the amplitude of the induced internal solitary wave. The imposing tidal flow superimposed on a constant mean background flow has a great damping effect on the induced internal waves, especially on those propagate against the background flow direction. The generation and propagation of internal solitary waves in three possible straits among the Luzon Strait are simulated, and the reasons for the asymmetry of their propagation are also explained. (C) 2002 Ifremer/CNRS/IRD/Éditions scientifiques et médicales Elsevier SAS. All rights reserved.
\end{abstract}

\section{Résumé}

Un nouveau modèle composite, associant un modèle de génération de marées internes et un modèle de propagation d'ondes longues régularisée est proposé pour l'étude de la génération et de l'évolution d'ondes solitaires internes dans un détroit à seuil. Les ondes de marée internes dans le détroit à seuil sont d'abord simulées par le modèle de génération ; le champ de marée interne à l'extérieur du seuil sert à initialiser le modèle de propagation. Des expériences numériques sont conduites pour étudier les effets de la marée imposée, du profil de profondeur, de la largeur du canal et des haut-fonds, etc. sur la génération et l'évolution des ondes solitaires internes. C'est seulement quand l'amplitude de la marée interne à la limite de forçage du modèle de propagation atteint une certaine valeur qu'un train d'ondes solitaires internes est induit. L'amplitude de la marée initiale dans le modèle de génération, l'effet de haut-fond, l'asymétrie du profil de profondeur et la largeur du canal agissent quelque peu sur l'amplitude de l'onde solitaire interne induite. Le flux de marée surimposé à un courant moyen constant a un effet majeur d'amortissement sur les ondes internes induites, spécialement sur celles qui se propagent contre la direction du courant moyen. La génération et la propagation d'ondes solitaires internes dans trois des seuils du détroit de Luzon sont simulées et les raisons de leur asymétrie de propagation sont également expliquées. (C) 2002 Ifremer/CNRS/IRD/Éditions scientifiques et médicales Elsevier SAS. Tous droits réservés.

Keywords: Internal wave; Soliton; Numerical model; South China Sea

Mots clés: Marée interne; Modèle numérique de soliton; Mer de Chine

\footnotetext{
* Corresponding author.

E-mail address: caisq@scsio.ac.cn (S. Cai).
} 


\section{Introduction}

In the last two decades, it is reported that the internal solitons near Dongsha Islands in the northern South China Sea (SCS) were very active Fett and Rabe 1977: Fang et al. 2000) . It is pointed out that the solitons north of Dongsha Islands were generated in a strait between Batan and Sabtang islands in the Luzon Strait (Fig. 1). Cai et al (2002) showed that the strait between Luzon and Fujia islands in the Luzon Strait might be another source of solitons south of Dongsha Islands. However, it seems that little numerical study has been carried out to explain the generation and propagation of internal solitary waves in the northern SCS. Moreover, it is observed that most internal waves in the north part of the SCS are propagating westward Hsu and Liu, 2000) while there are a few observations that the internal wave propagates eastward (toward the Pacific). How to explain this west-east asymmetry? Liu et al. (1998) used a KdV type equation with varying coefficients to simulate the evolution of the internal solitons in the SCS, where a well-developed soliton solution is given as an initial time-dependent boundary condition. However, a more general theoretical approach should imply the determination of the internal soliton (or tide) in the source by means of a generation model, whose input is given by the mean flow and tidal current (Longo et al, 1992).

In this paper, we mainly study the three possible sources for the generation and propagation of internal solitary waves in the Luzon Strait. Usually the problem is separated into a 'generation phase', for which the hydrostatic approximation is applied Hibiya, 1990; Longe et al, 1992) and a 'propagation phase', for which a nonhydrostatic description is required (Pierini, 1989. Brandt et al, 1996, 1997) The model we employed here is a composite of two models consisting of (1) a hydrostatic model developed by Brandtet al_(1997) which describes the dynamics of generation of the internal bores in the sill strait and (2) a one-dimensional regularized long wave (RLW) model developed by Caiet al (2002) which describes the dynamics of propagation and disintegration of the internal bores into internal solitary

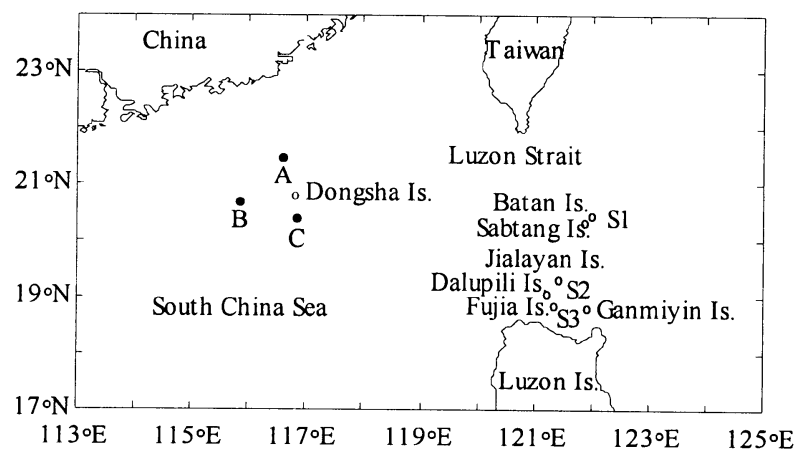

Fig. 1. Locations in the South China Sea where internal solitons were observed (A, B and C) and generated (S1, S2 and S3. S1 denotes the strait between Batan and Sabtang islands, S2 between Jialayan and Dalupili islands, while S3 between Fujia and Luzon islands). waves outside of the sill region where the internal bores are generated. In contrast to the composite model of Brandteet al. (1997), our model uses the computed internal tidal field by the generation model as the initial and boundary conditions to force the propagation model.

\section{Summary of the recent observations of internal solitons near Dongsha Islands}

Since Eett_and Rabe (1977) showed that there existed internal waves in the vicinity of Dongsha Islands in the SCS by a satellite photograph in May 1973, some progress has been made on the studies of the internal solitons here. The wave-induced current reported here may exceed $200 \mathrm{~cm} \mathrm{~s}^{-1}$ Cai_et al_2002). From the ERS-1 SAR images collected south of Taiwan in the Luzon Strait Hsw_and_Lim,2000) it is suggested that most of the internal waves are generated from the shallow topography or sill in the Luzon Strait. As currents within solitons generally are aligned with the direction of propagation, it seems that there are at least three possible sources. The strong solitons recorded at point A $\left(21^{\circ} 27.88^{\prime} \mathrm{N}, 116^{\circ} 37.75^{\prime} \mathrm{E}\right)$ had a mean direction of 279 310 ${ }^{\circ}$, which indicated that these internal solitons may be generated in the strait S1 (between Batan and Sabtang islands). While the strong solitons recorded at point $\mathrm{B}\left(20^{\circ}\right.$ $\left.22^{\prime} \mathrm{N}, 116^{\circ} 58^{\prime} \mathrm{E}\right)$ and $\mathrm{C}\left(20^{\circ} 21.311^{\prime} \mathrm{N}, 116^{\circ} 50.633^{\prime} \mathrm{E}\right)$ had a mean direction of 270-290 Eang et al_2000: Cai_et al.2001) which indicated that these internal solitons may be generated in the sill straits S2 (between Dalupili and Jialayan islands) and S3 (between Luzon and Fujia islands). However, up to now, there is no powerful evidence to support it.

\section{Numerical models}

The model presented here is a composite of two models consisting of (1) a generation model developed by Brandtet al_(1997) which describes the dynamics of generation of the internal bores in the sill and (2) a one-dimensional RLW model developed by Cai et al.(2002), which describes the dynamics of the possible propagation and disintegration of the internal bores into internal solitary waves outside of the sill region.

The two-layer generation model equations are as follows:

$$
\begin{gathered}
\frac{\partial Q_{i}}{\partial t}+\frac{\partial}{\partial x}\left(u_{i} Q_{i}\right)+h_{i} W \nabla P_{i}- \\
A_{H} h_{i} W \frac{\partial^{2} u_{i}}{\partial x^{2}}-W \frac{\tau_{i}-\tau_{i+1}}{\rho}=0 \\
\frac{\partial h_{i}}{\partial t}+\frac{1 \partial Q_{i}}{W \partial x}=0
\end{gathered}
$$




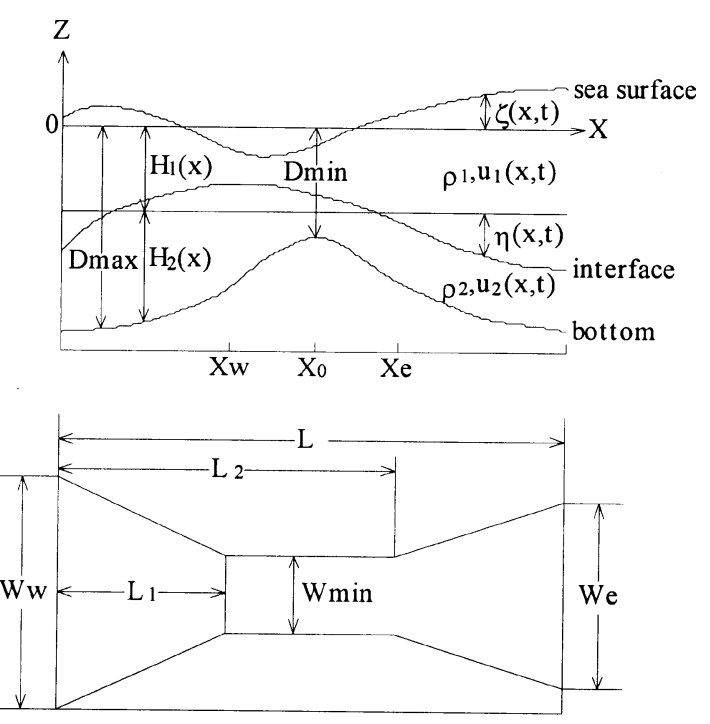

Fig. 2. Sketch of the two-layer model. (a) Depth profile; (b) channel width.

Here, the subscripts $i=1$ and $i=2$ refer to the upper layer and lower layer, respectively (Fig. 2). $\varrho_{i}$ is the water density, the transport is defined by $Q_{i}=u_{i} h_{i} W_{i}, u_{i}$ is the depth mean velocity, $g^{\prime}=g(\rho 2-\rho 1) / \rho=g \Delta \rho / \rho$ is the reduced gravity acceleration. $\tau_{1}, \tau_{2}$ and $\tau_{3}$ denote the wind stress (here we choose $\tau_{1}=0$ ), interfacial and bottom friction stress, those are computed using a quadratic law Brandt et al. 1997. Moreover, $h_{i}$ is the layer thickness, i.e. $h_{1}=H_{1}+\zeta-\eta, h_{2}=H_{2}+\eta$, where $H_{1}, H_{2}$ are the undisturbed thickness of the upper and lower layer, $\zeta$ and $\eta$ are free surface anomaly and pycnocline height anomaly. The pressure gradient in each layer is: $\nabla P_{1}=g \nabla \zeta, \nabla P_{2}=\nabla P_{1}-g \nabla h_{1} . A_{\mu}$ is horizontal eddy viscosity coefficient. Different from Brandt et_al_(1997) we differentiate Eqs. (1) and (2) on 'Arakawa C' grid using semi-implicit (three-time-level and five-point) scheme as employed by Hurlburt and Thompson (1980) In fact, Caiet bl. (2000) had used this numerical model to study the generation of internal tide in the continental shelf near Nansha Islands in the SCS. This two-layer system is applied in the whole strait and forced by imposing barotropic, semi-diurnal/diurnal tidal displacements at the two open boundaries.

The propagation model used here is an RLW equation model developed by Cai et al (2001) it is adapted from a $\mathrm{KdV}$ type evolution equation that formulated by Lim (1988) The model's equation about the wave amplitude $\eta$ (PHA) with variable coefficient is:

$$
\eta_{t}+c \eta_{x}+\alpha \eta \eta_{x}+\kappa \eta^{2} \eta_{x}-\frac{\beta \eta_{x x t}}{c}-\frac{1}{2} A_{H} \eta_{x x}+\gamma \eta=0
$$

Here, coefficients for the nonlinear, high-order nonlinear and dispersion effects are defined by $\alpha=\frac{3 H_{1}-H_{2}}{2 H_{1} H_{2}} c, \quad \kappa=-3 \frac{H_{1}^{2}-H_{1} H_{2}+H_{2}^{2}}{\left(H_{1} H_{2}\right)^{2}} c \quad$ and
Table 1

Values of parameters used in the numerical simulations

\begin{tabular}{lc}
\hline Grid space, $\Delta x$ & $50 \mathrm{~m}$ \\
Time step, $\Delta t$ & $3 \mathrm{~s}$ \\
$H_{1}$ & $80 \mathrm{~m}$ \\
$g$ & $0.0098 \mathrm{~m} \mathrm{~s}^{-2}$ \\
Horizontal eddy viscosity & $10 \mathrm{~m}^{2} \mathrm{~s}^{-1}$ \\
coefficient, $A_{H}$ & \\
Interfacial friction coefficient, $r_{\text {int }}$ & 0.001 \\
Bottom friction coefficient, $r_{\text {bot }}$ & 0.01
\end{tabular}

$\beta=\frac{1}{6} H_{1} H_{2} c$, and the phase speed $c$ is defined by $c=\left[g^{\prime} H_{1} H_{2} /\left(H_{1}+H_{2}\right)\right]^{1 / 2}$, while $\gamma$ is the coefficient for the shoaling effect, it has an order of $-2 \times 10^{-5} \mathrm{~s}^{-1}$ and depends on the gradient of bottom topography variation Lii, 1988). For convenience, we choose: $\gamma=\gamma_{0} D_{x} /\left|D_{x}\right|_{\max }$, here $D_{x}$ is the gradient of bottom topography variation along the $x$-axis, and the value of constant $\gamma_{o}$ will be specified in Section 4. In this model, the Orlanski radiation condition Orlanski.1976 is used at the end of the computational boundary, and the (two-time-level and threepoint) Crank-Nicholson scheme is used to differentiate Eq. (3) Cai et al_ 2002

We set the boundary west of the sill region at $X_{\mathrm{w}}(=35 \mathrm{~km}$, e.g.) and the boundary east of the sill region at $X_{\mathrm{e}}\left(=45 \mathrm{~km}\right.$, e.g.). For $x \leq X_{\mathrm{w}}$ or $x \geq X_{\mathrm{e}}$, the propagation model is applied. The propagation model is not set up until the generation model gets steady after running $24 \mathrm{~h}$, and the computed field of $\eta_{i}(t)$ for $x \leq X_{\mathrm{w}}$ and $x \geq X_{\mathrm{e}}$ (other than a well-developed soliton solution as used by Liu et al. (1998) is given as the initial conditions for the propagation model. And from then on, the computed time-variant internal tides $\eta_{i}(t+\Delta t)$ at $X_{\mathrm{w}}$ and $X_{\mathrm{e}}$ by the generation model are given as the boundaries conditions to force the propagation model. Thus in this composite model, the computed $\eta_{i}(t+\Delta t)$ for $x<X_{\mathrm{w}}$ and $x>X_{\mathrm{e}}$ in the propagation model have no relation with that in the generation model, which is different from the composite model of Brandt et al (1997). The other parameters used in the numerical simulation cases are given in Table 1.

\section{Numerical simulations}

\subsection{Sensitive experiments}

The depth profile and channel width are assumed to have the following form (Fig. 2):

$$
D=\left\{\begin{array}{l}
D_{\text {max }}-\left(D_{\max }-D_{\min }\right) \cosh ^{-2}\left(\frac{x-X_{0}}{L} S_{1}\right), x \leq X_{0} \\
D_{\text {max }}-\left(D_{\max }-D_{\min }\right) \cosh ^{-2}\left(\frac{x-X_{0}}{L} S_{2}\right), x>X_{0}
\end{array}\right.
$$




$$
W=\left\{\begin{array}{c}
\left(W_{w}-W_{\min }\right) \frac{L_{1}-x}{L_{1}}+W_{\min }, x \leq L_{1} \\
W_{\min }, L_{1}<x \leq L_{2} \\
\left(W_{e}-W_{\min }\right) \frac{x-L_{2}}{L-L_{2}}+W_{\min }, x>L_{2}
\end{array}\right.
$$

where $D_{\max }$ is the maximum water depth, $D_{\min }$ the minimum water depth (at the sill $x=X_{0}$ ), and $L$ the length of the channel. $W_{\mathrm{w}}$ is the width at the western boundary, $W_{\min }$ the minimum width of the channel, and $W_{\mathrm{e}}$ the width at the eastern boundary. $s_{1}$ and $s_{2}$ are the westward and eastward slope coefficients of the sill. Here we choose: $D_{\max }=1000 \mathrm{~m}, \quad D_{\min }=160 \mathrm{~m}, \quad W_{\min }=10 \mathrm{~km}$, $W_{\mathrm{w}}=W_{\mathrm{e}}=20 \mathrm{~km}, L_{1}=30 \mathrm{~km}, L_{2}=50 \mathrm{~km}, L=80 \mathrm{~km}$, $s_{1}=s_{2}=16$. Moreover, $\gamma_{0}=0, X_{\mathrm{w}}=35 \mathrm{~km}, X_{\mathrm{e}}=45 \mathrm{~km}$, $X_{0}=40 \mathrm{~km}$. The imposing barotropic tide at the boundaries has the form:

$$
\zeta=A_{0}+A \cos (\omega t-\theta)
$$

Here, $A_{0}$ is the mean sea surface height (usually $A_{0}=0$ ), $A$ the tide amplitude, $\omega$ the frequency and $\theta$ the phase lag.

At first, we test the sensitivity of the simulation results to the different imposing tidal conditions, such as the change of the phase difference $\Delta \theta\left(=\left.\theta\right|_{\mathrm{x}=80 \mathrm{~km}}-\left.\theta\right|_{x=0}\right)$ and tide amplitude $A$ for $\mathrm{M}_{2}$ tide, or when the imposing tide is a diurnal or mixed one. The experimental cases are given in Table 2.

\subsubsection{Experiments on the effect of imposing tide}

4.1.1.1. Experiments on the effect of phase difference between the western and eastern boundaries for $M_{2}$ tide. Three cases (experiments E1, E2 and E3) with different phase differences between the western and eastern boundaries for $\mathrm{M}_{2}$ tide are studied: (a) $\Delta \theta=180^{\circ}$, (b) $\Delta \theta$ $=30^{\circ}$ and (c) $\Delta \theta=5^{\circ}$. Among them, the tidal current field is strong in experiment $\mathrm{E} 1$, moderate in experiment $\mathrm{E} 2$ and weak in experiment E3. The case in experiment E1 when $\Delta \theta=180^{\circ}$ (Fig. 3) is very similar to the simulation result of internal waves in the Strait of Messina Brandt_et al 1997). At maximum eastward tidal flow, the interface at the

Table 2

Experimental cases for different imposing tidal conditions

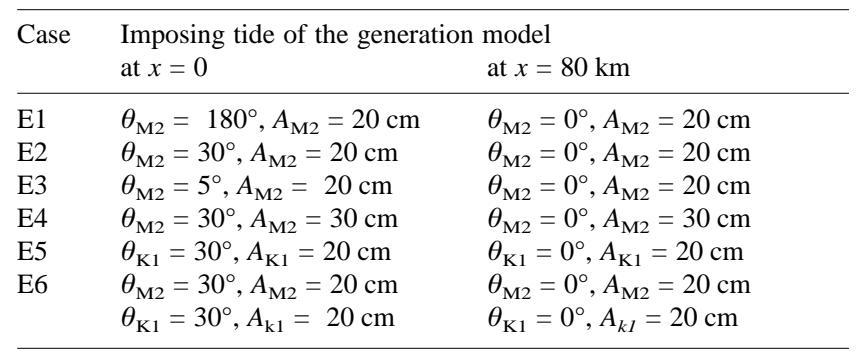
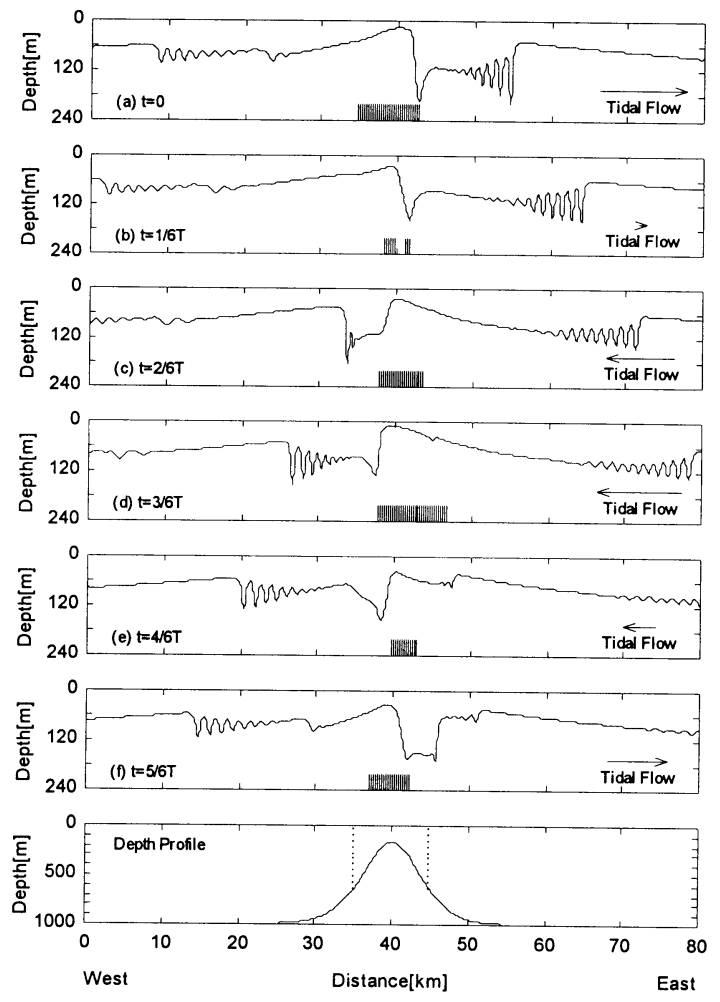

Fig. 3. Space-time evolution of the interface depth between the two water layers in the case of $\Delta \theta=180^{\circ}$. The time $t=0$ corresponds to maximum eastward tidal flow. The black shaded areas mark the regions where the flow is supercritical. The dotted vertical lines in the bottom panel separate the model domain into two propagation regions west and east of the sill. They are corresponding to the boundaries of the propagation model at $x=$ $X_{\mathrm{w}}$ and $x=X_{\mathrm{e}}$.

sill is lifted upward, while an interfacial depression east of the sill is present. At slack tide the depression starts propagating westward toward the sill. After the bore strides the sill, it is released and gives birth to a train of rankordered internal solitary waves, which propagate westward. At maximum westward tidal flow, the interface at the sill is again lifted upward, while an internal bore west of the sill is present. As discussed for the evolution of the westward propagating internal bore, this bore passes the sill and disintegrates into a train of internal solitary waves, which propagate eastward. In the figure, the interface depth for six different times separated by $1 / 6$ of the tidal cycle with period $T=12.4 \mathrm{~h}$ is shown (note that, the solution of the interface depth for $X_{\mathrm{w}}<x<X_{\mathrm{e}}$ is from the generation model, while solutions for $x \leq X_{\mathrm{w}}$ and $\mathrm{x} \geq X_{\mathrm{e}}$ are from the propagation model). The arrows indicate the direction and the strength of the tidal flow at the sill. The short black shaded areas in each panel mark the regions where the composite Froude number $F$, defined by

$$
F^{2}=\frac{u_{1}^{2}}{g^{\prime} h_{1}}+\frac{u_{2}^{2}}{g^{\prime} h_{2}}
$$

is larger than 1 and thus the flow is supercritical. 
The same scenario happens in experiment E2 when $\Delta \theta=30^{\circ}$. However, the amplitudes of the generating internal waves are smaller than those in experiment E1. While in experiment $\mathrm{E} 3$ when $\Delta \theta=5^{\circ}$, there is no indication of the generation of internal bore or internal solitary waves. After comparing the internal tide at $X_{\mathrm{w}}$ and $X_{\mathrm{e}}$ (computed by generation model and given as the boundary conditions of propagation model) in experiment E1, E2 and E3 (e.g. Fig. 4a shows the time series of the interface depth at $X_{\mathrm{w}}$ in these three experiments), it is found that the generation of internal solitary waves seems to be related to the amplitude of internal tide at boundary $X_{\mathrm{w}}$ and $X_{\mathrm{e}}$, i.e. when the amplitude of internal tide at boundary is large enough, a train of internal solitary waves would be induced, while when the amplitude of internal tide at boundary is too small, no internal solitary wave would be induced. In fact, it is common to find internal tide in most stratified oceans, however, only when the amplitude of internal tide is large enough could the internal solitary wave be induced there. Note that the shapes and amplitudes of the eastward and westward propagating internal solitary waves are very different. Brandt_et_al_(1997) attributed it to the west-east asymmetry of the channel width, however, in our case not only the channel width but also the depth profile are symmetric. Therefore, the above difference is related to the west-east asymmetry of the amplitude of internal tide at $X_{\mathrm{w}}(=35 \mathrm{~km})$ and $X_{\mathrm{e}}(=45 \mathrm{~km})$, e.g. Fig. $4 \mathrm{~b}$ shows that the amplitude of internal tide at $X_{\mathrm{w}}$ is smaller than that at $X_{\mathrm{e}}$ in experiment E1. Moreover, we can also see that, in experiments E1 and E2, when the computed internal tide at $X_{\mathrm{w}}$ (or $X_{\mathrm{e}}$ ) changes suddenly from high water to low water, a train of internal solitary waves would be induced. For example, in experiment E1, the internal tide at $X_{\mathrm{w}}$ changes suddenly from wave crest to wave hollow (i.e. the interface deepens sharply) from $87 \mathrm{~h}$ to $88 \mathrm{~h}$, thus a train of westward internal solitary waves is induced during the same period. In experiment E3, however, the changing amplitude of internal tide at $X_{\mathrm{w}}$ is distinctly not large enough to induce internal solitary wave.

Since in the Luzon Strait, the tidal phase differences between the western and eastern boundaries of the sill channel are basically less than $30^{\circ}$, thus in the following we choose the experiment E2 as the standard experiment.

\subsubsection{Experiments on the effect of amplitude difference between the western and eastern boundaries for $\mathrm{M}_{2}$ tide. As expected, in experiment E4 when the amplitude of the imposing tide increases, the simulation result is very similar to that in experiment E2, except that now because the amplitudes of the generated internal tides at $X_{\mathrm{w}}$ and $X_{\mathrm{e}}$ increase, the amplitudes of the generated internal solitary waves thus increase correspondingly.}

4.1.1.3. Experiment on the effect of imposing diurnal tide. In experiment E5, when the imposing tide is a $\mathrm{K}_{1}$ tide (whose period is about $25.8 \mathrm{~h}$ ), the simulation result is also

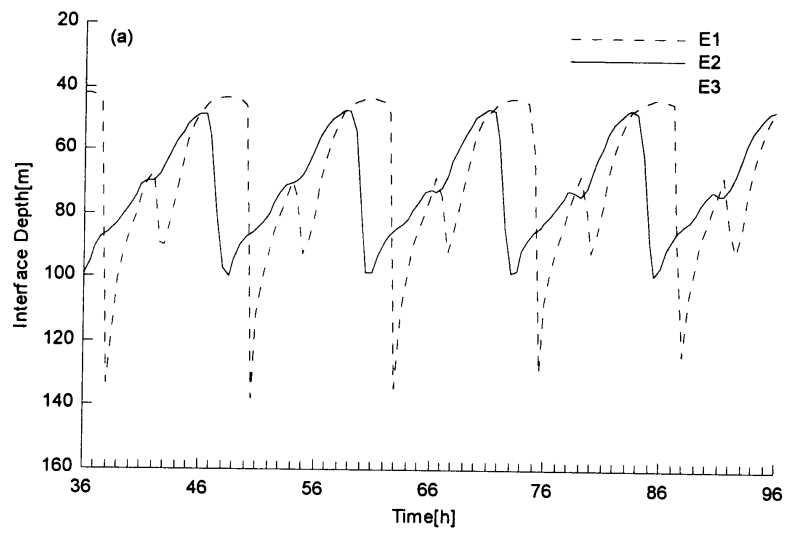

Fig.4a

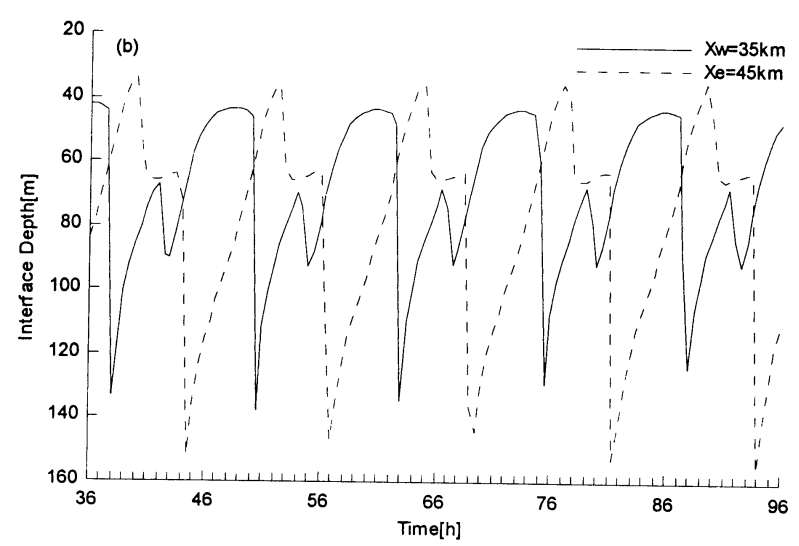

Fig. 4. Comparison of the time series of the interface depths (a) at $x=35$ $\mathrm{km}$ in experiments $\mathrm{E} 1\left(\Delta \theta=180^{\circ}\right), \mathrm{E} 2\left(\Delta \theta=30^{\circ}\right)$ and $\mathrm{E} 3\left(\Delta \theta=5^{\circ}\right),(\mathrm{b})$ at $x=35 \mathrm{~km}$ and $x=45 \mathrm{~km}$ in experiment $\mathrm{E} 1\left(\Delta \theta=180^{\circ}\right)$.

very similar to that in experiment E2, except that now the generation period of internal solitary waves changes to be about $25.8 \mathrm{~h}$ correspondingly.

4.1.1.4. Experiment on the effect of imposing mixed tide. In experiment E6, when the imposing tide is a mixed tide of $M_{2}$ and $K_{1}$, the tidal current is irregular. The release of the westward propagating internal solitary wave train seems to correspond to the maximum westward tidal flow (Fig. 5), however, the release of the eastward one only happens in one of the moments when the eastward tidal current becomes maximum. Since the tidal period is not so regular as that in experiment E2, and the time when the amplitude of the internal tide at the forcing boundary of the propagation model becomes large enough to induce internal solitary waves is unpredictable, thus the generation time of the internal solitary waves is unpredictable. 


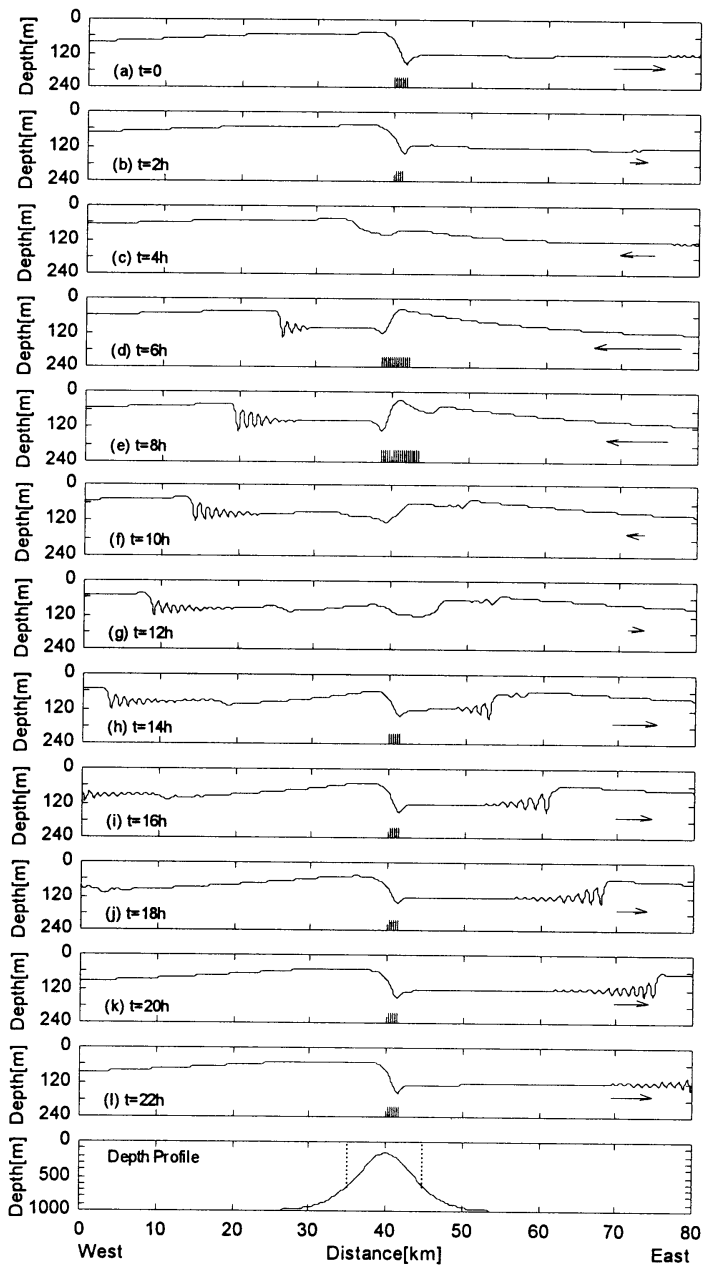

Fig. 5. Evolution of the interface depth every $2 \mathrm{~h}$ for 12 different times for the case that the imposing tide is a mixed tides of $\mathrm{M}_{2}$ and $\mathrm{K}_{1}$ (experiment E6).

\subsubsection{Experiments on the effects of external conditions.} Secondly, we test the sensitivity of the simulation results to the other external conditions, including the set of the eastern and western boundaries of the propagation model, shoaling effect, the asymmetry of the channel width and depth profile, and background constant flow. The difference of the standard experiment E2 from the other experiments are given in Table 3.

Table 3

Different experimental cases based on the standard experiment E2

E7 Same as E2, except that $X_{\mathrm{w}}=30 \mathrm{~km}$ and $X_{\mathrm{e}}=50 \mathrm{~km}$

E8 Same as E2, except that $\gamma_{o}=-1 \times 10^{-5} \mathrm{~s}^{-1}$

E9 Same as E2, except that $W_{\mathrm{w}}=30 \mathrm{~km}$

E10 Same as E2, except that $s_{1}=16$ and $s_{2}=1$

E11 Same as E2, except that $s_{1}=1$ and $s_{2}=16$

E12 Same as E2, except that at $x=0$ the mean sea surface height $A_{0}$ is $2 \mathrm{~cm}$ lower than that at $x=80 \mathrm{~km}$
4.1.1.6. Experiment on the effect of boundaries locations. In experiment E7, when the boundaries of the propagation model are moved $5 \mathrm{~km}$ westward and eastward from the sill, respectively, the amplitudes of the induced internal solitary waves are smaller when compared with those in experiment E2. This result agrees with the above conclusion, since now the computed amplitudes of internal tide at the boundary of the propagation model are smaller than those in experiment E2. The result that the amplitude of internal tide near the sill is larger than that far from the sill also agrees with the conclusion of Longo et al. (1992).

4.1.1.7. Shoaling effect experiment. In experiment E8, when the shoaling effect is considered $\left(\gamma_{0}=-1 \times 10^{-5} \mathrm{~s}^{-1}\right)$, the simulation result agrees with the conclusion of Liil 1988] when compared with that in experiment E2, i.e. with shoaling effect in experiment E8, the propagating solitary wave packet decays more slowly than that in experiment E2.

4.1.1.8. Experiment on the effect of channel width. In experiment E9, when the western part of the channel is widened $\left(W_{\mathrm{w}}=30 \mathrm{~km}\right)$, the simulation result agrees with conclusion of Brandt_et_al_(1997) i.e. because in the western section the channel is wider, the westward propa gating solitary wave packet is attenuated more strongly than that in experiment $\mathrm{E} 2$.

4.1.1.9. Slope effect experiment. Two cases with different westward and eastward slope coefficients of the sill are studied: (a) experiment E10 with $s_{1}=16$ and $s_{2}=1$, and (b) experiment E11 with $s_{1}=1$ and $s_{2}=16$. Fig. 6a shows that the amplitude of internal tide at $X_{\mathrm{w}}=35 \mathrm{~km}$ is larger than that at $X_{\mathrm{e}}=45 \mathrm{~km}$ (in experiment E10), while Fig. 6b shows that the amplitude of internal tide at $X_{\mathrm{w}}=35 \mathrm{~km}$ is smaller than that at $X_{\mathrm{e}}=45 \mathrm{~km}$ (in experiment E11). Thus, according to the results of these two experiments, it is shown that a train of internal solitary waves would be induced only in one side of the sill where the slope is steeper and the amplitude of internal tide at boundary of the generation model is large enough, while in the other side of the sill where the slope is more gentle and the amplitude of internal tide at boundary of the generation model is smaller, no distinct internal solitary wave would be induced.

4.1.1.10. Experiment on the effect of mean sea surface height. In experiment E12, we suppose the mean sea surface height $A_{O}$ at $x=0$ is $2 \mathrm{~cm}$ lower than that at $x=80 \mathrm{~km}$, which represents that there is a westward background constant flow for a channel. Fig. 7 shows that the amplitude of internal bore that propagates to the west of the sill is larger than that which propagates to the east. This agrees with the conclusion that the internal tidal depression that propagates toward the Mediterranean has a larger amplitude than that propagating toward the Atlantic in the numerical simulation of the strait of Gibraltar with tidal flow 


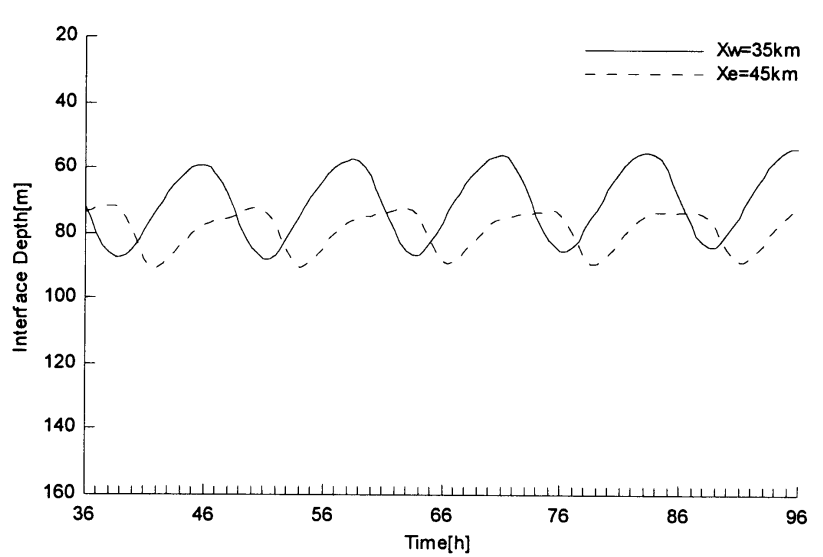

Fig.6a

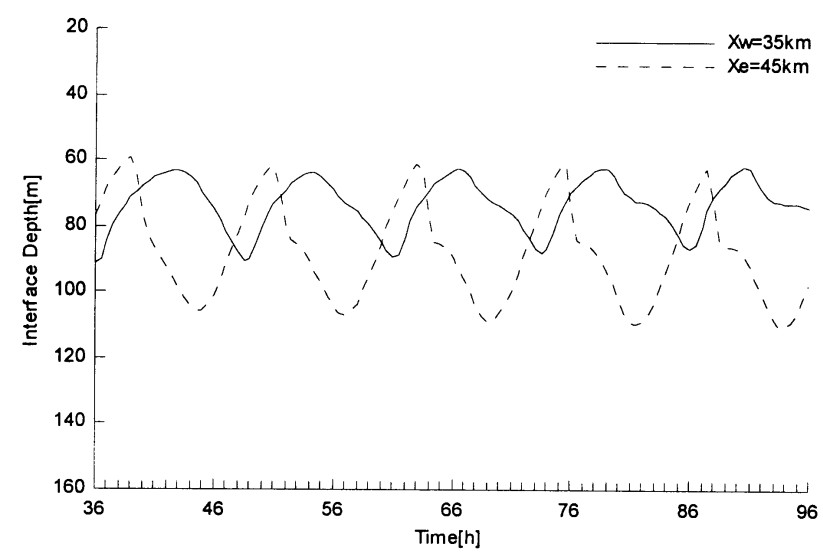

Fig. 6. Comparison of the time series of the interface depth at $x=35 \mathrm{~km}$ with that at $x=45 \mathrm{~km}$ (a) in experiment E10, (b) in experiment E11.

superimposed on an eastward constant mean flow Longo et 6l. 1992. However, now both the westward and eastward trains of internal solitary waves are attenuated strongly (when compared with that in experiment E2), and the amplitudes of the westward train are somewhat larger than those of the eastward train. Thus, the westward background constant flow seems to have a large damping effect on the internal waves, especially on the waves propagating against the background flow direction.

\subsection{Simulations of internal solitary waves in the straits S1, S2 and S3 among the Luzon Strait}

In the model calculations in this section, although the straits S1, S2 and S3 are very short, we extend them to $80 \mathrm{~km}$, and the width of the channel are also idealized. The basic parameters are as shown in Table 1. Four local major components of tide $\mathrm{M}_{2}, \mathrm{~S}_{2}, \mathrm{~K}_{1}$ and $\mathrm{O}_{1}$ are considered, and
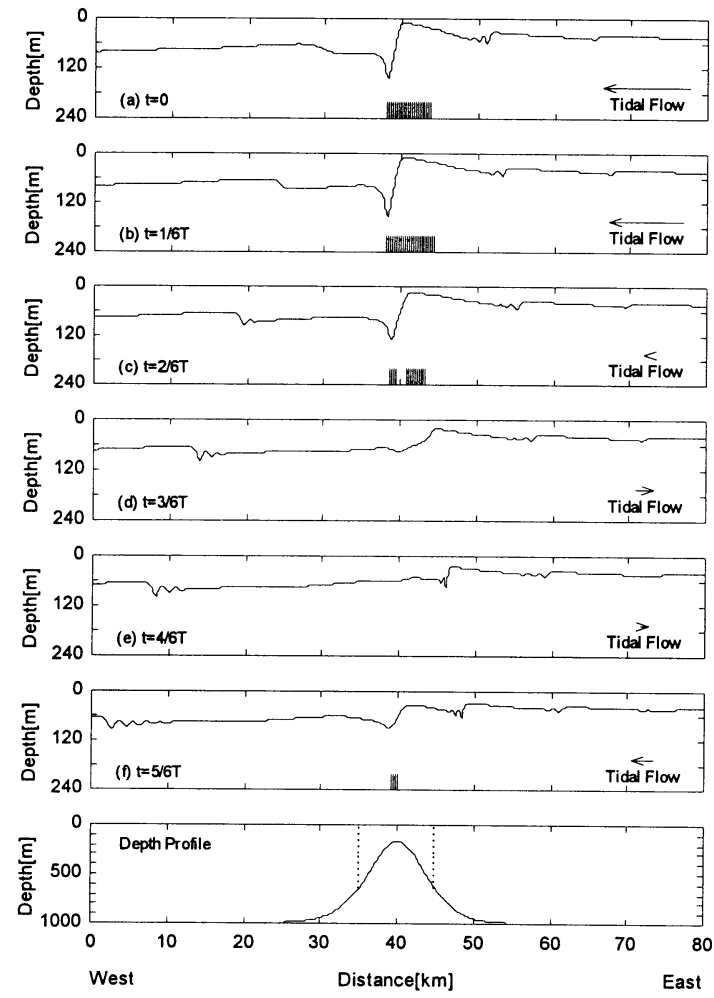

Fig. 7. Same as in Fig. 3 but for the case that there is a background westward flow and $\Delta \theta=30^{\circ}$ (experiment E12).

their harmonic constants, which are interpolated by the computed results from Eang et al__(1999) are shown in Table 4. Since the tidal nature is irregular semi-diurnal in these cases, Figs. 8-10 only give the evolution of the interface depth every $2 \mathrm{~h}$ for 12 different times in these straits with their corresponding idealized depth profile and channel width. It is shown that the westward (toward the SCS) and eastward (toward the Pacific) propagating trains of internal solitary waves are induced in these three straits. In strait S1, the depth profile of the channel is almost symmetric, so the induced westward and eastward propagating trains of internal solitary waves are symmetric by and large, as discussed in Section 4.1. In strait S2, the westward and eastward propagating trains of internal solitary waves still can be induced, however, since the eastern part of the channel is relatively shallow (and there is still a small sea mount at $x=70 \mathrm{~km}$ ), the eastward wave train seems to attenuate more strongly during its propagation than the westward train. The eastward train almost dissipates before it gets to the eastern boundary. Therefore, it implies that the sea mount seems to have a large damping (dissipative) effect on the internal solitary wave. In strait S3, the amplitudes of the induced westward and eastward propagating trains of internal solitary waves are very weak since the topography is less steep, and as the case discussed in strait S2, the eastward propagating train of internal solitary waves is damped strongly by the shallow topography. 
Table 4

Experimental cases for imposing tidal conditions in straits S1, S2 and S3

Case Imposing tide of the generation model

$$
\text { at } x=0 \quad \text { at } x=80 \mathrm{~km}
$$

E13 $\theta_{\mathrm{M} 2}=182.0^{\circ}, A_{\mathrm{M} 2}=22.0 \mathrm{~cm} \quad \theta_{\mathrm{M} 2}=165.5^{\circ}, A_{\mathrm{M} 2}=25.8 \mathrm{~cm}$

$\theta_{\mathrm{S} 2}=200.2^{\circ}, A_{\mathrm{S} 2}=9.2 \mathrm{~cm} \quad \theta_{\mathrm{S} 2}=187.2^{\circ}, A_{\mathrm{S} 2}=11.1 \mathrm{~cm}$

$\theta_{\mathrm{K} 1}=260.5^{\circ}, A_{\mathrm{k} 1}=10.7 \mathrm{~cm} \quad \theta_{\mathrm{K} 1}=257.6^{\circ}, A_{\mathrm{k} 1}=9.7 \mathrm{~cm}$

$\theta_{\mathrm{O} 1}=223.6^{\circ}, A_{\mathrm{O} 1}=11.2 \mathrm{~cm} \quad \theta_{\mathrm{O} 1}=221.1^{\circ}, A_{\mathrm{O} 1}=10.9 \mathrm{~cm}$

E14 $\theta_{\mathrm{M} 2}=195.3^{\circ}, A_{\mathrm{M} 2}=13.3 \mathrm{~cm} \quad \theta_{\mathrm{M} 2}=170.0^{\circ}, A_{\mathrm{M} 2}=23.0 \mathrm{~cm}$

$\theta_{\mathrm{S} 2}=207.8^{\circ}, A_{\mathrm{S} 2}=5.4 \mathrm{~cm} \quad \theta_{\mathrm{S} 2}=197.7^{\circ}, A_{\mathrm{S} 2}=9.7 \mathrm{~cm}$

$\theta_{\mathrm{K} 1}=295.0^{\circ}, A_{\mathrm{k} 1}=13.2 \mathrm{~cm} \quad \theta_{\mathrm{K} 1}=276.0^{\circ}, A_{\mathrm{k} 1}=11.9 \mathrm{~cm}$

$\theta_{\mathrm{O} 1}=247.9^{\circ}, A_{\mathrm{O} 1}=13.6 \mathrm{~cm} \quad \theta_{\mathrm{O} 1}=238.2^{\circ}, A_{\mathrm{O} 1}=14.5 \mathrm{~cm}$

E15 $\theta_{\mathrm{M} 2}=189.7^{\circ}, A_{\mathrm{M} 2}=13.7 \mathrm{~cm} \quad \theta_{\mathrm{M} 2}=175.1^{\circ}, A_{\mathrm{M} 2}=21.5 \mathrm{~cm}$

$\theta_{\mathrm{S} 2}=203.3^{\circ}, A_{\mathrm{S} 2}=5.7 \mathrm{~cm} \quad \theta_{\mathrm{S} 2}=196.5^{\circ}, A_{\mathrm{S} 2}=9.0 \mathrm{~cm}$

$\theta_{\mathrm{K} 1}=296.1^{\circ}, A_{\mathrm{k} 1}=12.5 \mathrm{~cm} \quad \theta_{\mathrm{K} 1}=281.6^{\circ}, A_{\mathrm{k} 1}=11.7 \mathrm{~cm}$

$\theta_{\mathrm{O} 1}=248.7^{\circ}, A_{\mathrm{O} 1}=13.3 \mathrm{~cm} \quad \theta_{\mathrm{O} 1}=242.0^{\circ}, A_{\mathrm{O} 1}=14.3 \mathrm{~cm}$

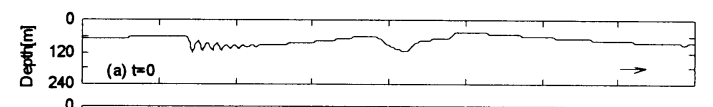

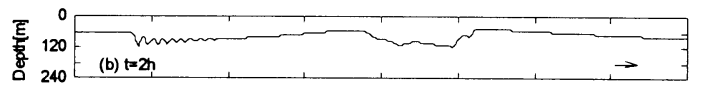

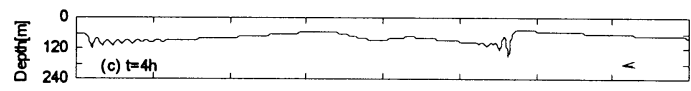

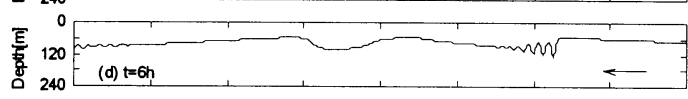

悉 ${ }_{240}^{0}{ }_{240}^{0}$

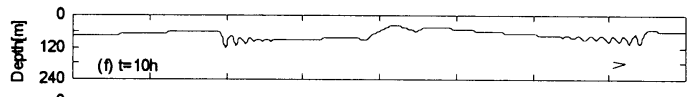

焉 ${ }_{240}^{2}{ }_{(\mathrm{g}) \mathrm{t}=12 \mathrm{~h}}$

$\sum_{0}^{\frac{E}{5}}{ }_{240}^{0} \overbrace{(\mathrm{h}) \mathrm{t}=14 \mathrm{~h}}$

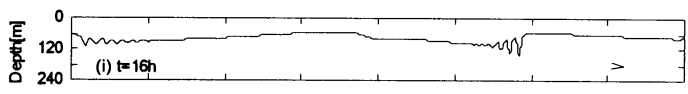

$\sum_{240}^{E_{0}}{ }_{120}^{0} \overbrace{(j) \mathrm{t}=18 \mathrm{~h}}$

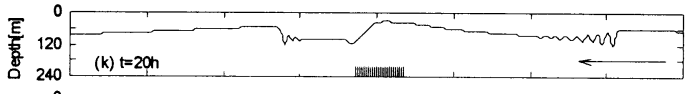

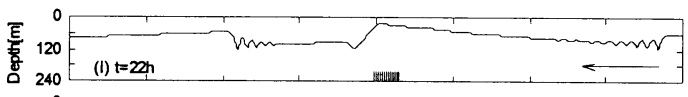

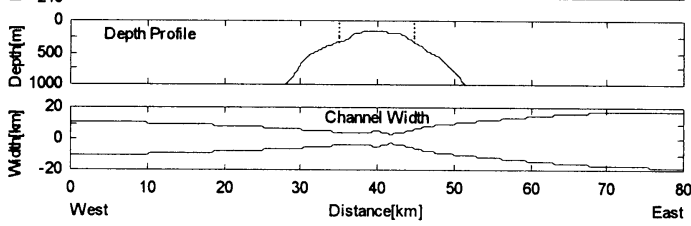

Fig. 8. Evolution of the interface depth every $2 \mathrm{~h}$ for 12 different times for the case in strait S1 (experiment E13), the approximated depth profile and channel width are also shown in the last two panels.

\section{Discussions and conclusions}

In this paper, a composite model consisting of a generation model of the internal tides and a RLW propagation model is employed to study the generation and evolution of internal solitary waves in the sill strait. At first, internal

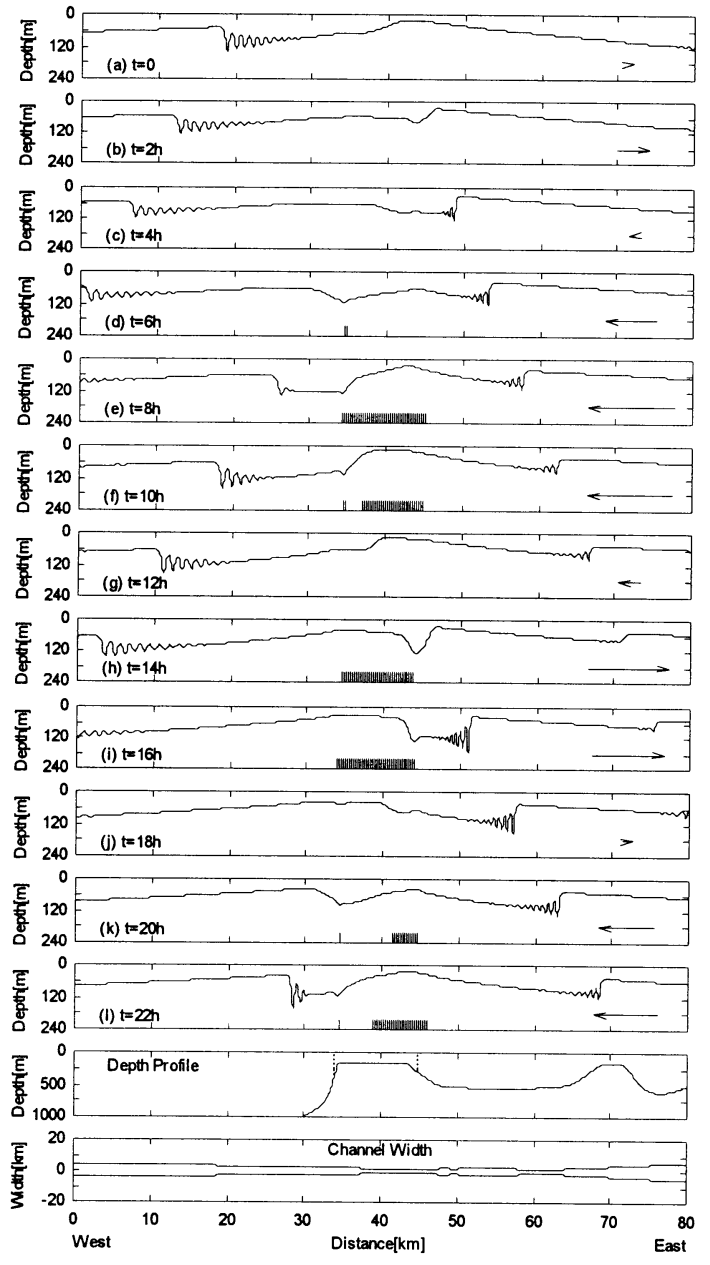

Fig. 9. Same as in Fig. 8 but for the case in strait S2 (experiment E14).

bores in the sill strait are simulated by the generation model, and then the internal tidal field outside of the sill region is given as the initial and boundary condition to set up the propagation model. Some numerical experiments are carried out to study the imposing tide, depth profile, channel width and shoaling effect, etc., on the generation and evolution of internal solitary waves. In the Korteweg-de Vries (or RLW) type simulation model with a well-developed soliton solution used as an initial condition, the internal solitary wave can always be induced (e.g. Limetal, 1998). However, in our composite model, it is shown that only when the amplitude of internal tide at the forcing boundary of the propagation model is large enough would a train of internal solitary waves be induced. Moreover, only the depression (but not elevation) internal solitary waves are induced because the initial upper layer thickness is smaller than the lower layer thickness in the propagation source. The amplitude of the imposing tide in the generation model, shoaling effect, asymmetry of the depth profile and channel width have some effects on the amplitude of the induced internal solitary wave. Tidal flow superimposed on a constant mean background flow has a great damping effect on the induced 


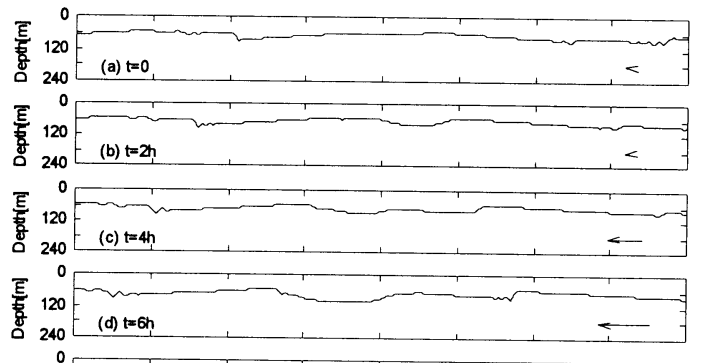

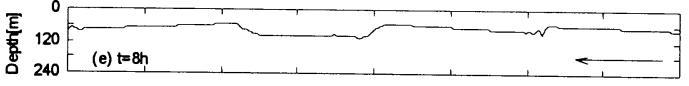

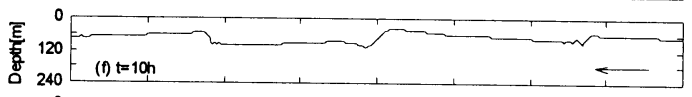

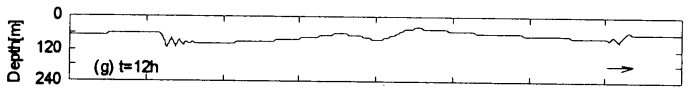

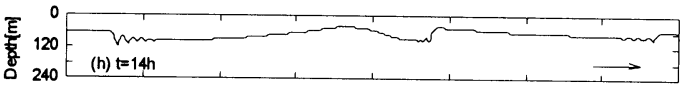

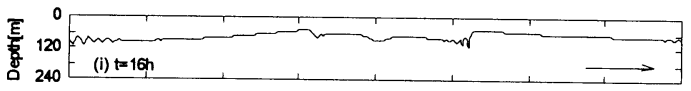

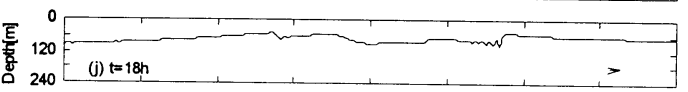

案 ${ }_{240}^{2}{ }_{24}^{0}(\mathrm{k}) \mathrm{t=20 \textrm {h }}, \ldots$
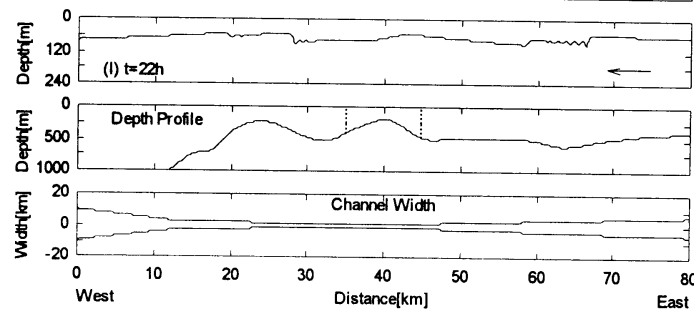

Fig. 10. Same as in Fig. 8 but for the case in strait $\mathrm{S} 3$ (experiment E15).

internal solitary waves, especially on those propagate against the background flow direction.

The generation and propagation of the internal solitary waves in straits S1, S2 and S3 among the Luzon Strait are simulated. In strait S1, due to the intrusion of Kuroshio into the SCS, the observational background mean flow here is mainly westward (Nitani, 1972) however, due to lack of observational data, no background flow is considered in the simulation, thus the induced westward and eastward propagating trains of internal solitary waves are distinct. According to the inference in Section 4.1, it is expected that the eastward internal solitary wave train would be damped largely if a background westward flow was superimposed in the simulation. In straits S2 and S3, the eastward propagating trains of internal solitary waves are induced all the same, however, the shallow topography in these eastern part of the channels has a great damping effect on these solitary waves during their propagation. And finally, after leaving their eastern boundaries, these solitary wave trains induced in straits S1 and S2 may run into the Ganmiyin Island and Luzon Island, respectively, and then be reflected or damped at last. Thus, in the Luzon Strait, most internal waves are observed to propagate westward into the northern SCS, other than propagate eastward to the Pacific Hsu and_Lim 2000).

It is interesting that during the mooring observation at point A (Fig. 1) from June to July, 1998, our researchers found that sometimes a train of internal solitons passed under the research ship at almost the same time every day, but sometimes they found no indication of the passage of internal soliton. This may be related to the complex irregular tidal nature in the Luzon Strait, thus as discussed in experiment E7, the generation time (and thus the propagation) of the internal soliton in the Luzon Strait is unpredictable.

After all, our simulation is very rough and tentative, thus, enough observational data and two-dimensional model are necessary for the future work.

\section{Acknowledgements}

Authors are indebted to the anonymous referees for helpful comments. This work is supported by Grant 40006003 from Chinese National Science Foundation and Grant 990310 from Guangdong Provincial Nature Science Foundation of China and also by LDPSD, SDA.

\section{References}

Brandt, P., Alpers, W., Backhaus, J.O., 1996. Study of the generation and propagation of internal waves in the Strait of Gibraltar using a numerical model and synthetic aperture radar images of the European ERS -1 satellite. J. Geophys. Res. 101, 14237-14252.

Brandt, P., Rubino, A., Alpers, W., 1997. Internal waves in the Strait of Messina studied by a numerical model and synthetic aperture radar images from the ERS $1 / 2$ satellites. J. Phys. Oceanogr. 27, 648-663.

Cai, S., Chen, R., Qiu, Z., 2000. Numerical study about the influence of bottom topographic change on the generation of internal tide. J. Oceanogr. Taiwan Strait 19 (1), 74-81 (in Chinese with English abstract).

Cai, S., Gan, Z., Long, X., 2001. Some characteristics and evolution of the internal soliton in the northern South China Sea. Chinese Sci. Bull (in press).

Fang, G., Kwok, Y.Y., Yu, K., 1999. Numerical simulation of principal tidal constituents in the South China Sea, Gulf of Tonkin and Gulf of Thailand. Continental Shelf Res. 19, 845-869.

Fang, W., Chen, R., Mao, Q., 2000. Abrupt strong currents over continental slope of northern South China Sea. Trop. Oceanol. 19 (1), 70-75 (in Chinese, English abstract).

Fett, R.W., Rabe, K., 1977. Satellite observation of internal wave refraction in the South China Sea. Geophys. Res. Lett. 4 (5), 189-191.

Hibiya, T., 1990. Generation mechanism of internal waves by a vertically sheared tidal flow over a sill. J. Geophys. Res. 95, 1757-1764.

Hsu, M.K., Liu, A.K., 2000. Nonlinear internal waves in the South China Sea. Can. J. Remote Sens. 26, 72-81.

Hurlburt, H.E., Thompson, J.D., 1980. A numerical study of Loop Current intrusions and eddy shedding in Gulf of Mexico. J. Phys. Oceanogr. 10, 1611-1631. 
Nitani, H., 1972. Beginning of the Kuroshio. In: Stommel, H., Yoshida, K (Eds.), Kuroshio: Its Physical Aspects. University of Washington Press, Seattle, Washington, pp. 129-163.

Liu, A.K., 1988. Analysis of nonlinear internal waves in the New York Bight. J. Geophys. Res. 93 (C10), 12317-12329.

Liu, A.K., Chang, Y.S., Hsu, M.K., 1998. Evolution of nonlinear internal waves in the east and south China Seas. J. Geophys. Res. 103 (C4), $1613-1624$.

Longo, A., Manzo, M., Pierini, S., 1992. A model for the generation of nonlinear internal tides in the Strait of Gibraltar. Oceanol. Acta 15, 233-243.
Maxworthy, T., 1979. A note on the internal solitary waves produced by tidal flow over a three-dimensional ridge. J. Geophys. Res. 84C, $338-346$.

Orlanski, I., 1976. A simple boundary condition for unbounded hyperbolic flows. J. Comput. Phys. 21, 251-269.

Osborne, A.R., Burch, T.L., 1980. Internal solitons in the Andaman Sea. Science 208, 451-460.

Pierini, S., 1989. A model for the Alboran Sea internal solitary waves. J. Phys. Oceanogr. 19, 755-772.

Rattray Jr, M., 1960. On the coastal generation of internal tides. Tellus 12, $54-62$. 